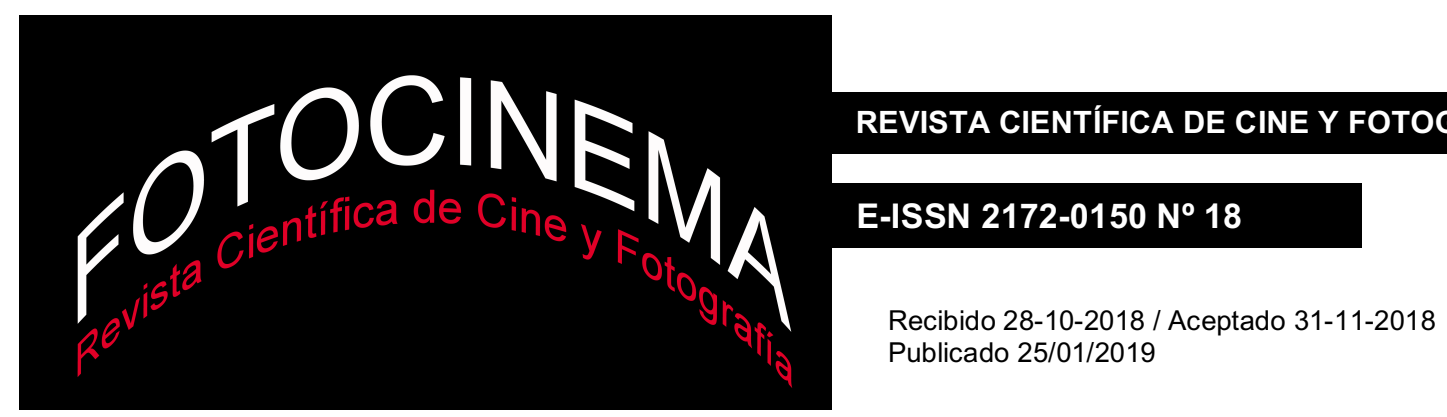

\title{
Palabras e imágenes del underground en 1,2,3 al escondite inglés (Iván Zulueta, 1970)
}

\section{Words and images of the underground culture in the filme 1,2,3 al escondite inglés (Iván Zulueta, 1970)}

\author{
Elena Rosillo \\ Universidad Rey Juan Carlos, España \\ e.rosillosf@gmail.com
}

\section{Resumen:}

En 1,2,3, al escondite inglés (1970) Iván Zulueta narra el deseo de un grupo de jóvenes por desbaratar el "Festival de la Canción de MundoCanal" (una parodia de Eurovisión). Para ello se rodea de actuaciones musicales de las principales bandas de la "modernidad" española del momento, como Los Ángeles o Fórmula V, entre otros. La cinta muestra, más allá de la música alternativa de la época, imágenes, gestos y diálogos que nos ayudan a encontrar las líneas definitorias de lo que podemos dar en llamar la cultura underground durante el Franquismo. En este artículo se pretende profundizar en la significación de algunos de estos diálogos (en su mayor parte jocosos), así como la imagen que se ofrece de las distintas formaciones musicales y los personajes de la historia, para reconocer las actitudes contraculturales que marcaron una cultura sometida por una ideología hegemónica, la franquista, en una ciudad en la que poco podía esperarse el desarrollo de una contracultura, como era Madrid.

\begin{abstract}
:
In 1,2,3, al escondite inglés (1970) Iván Zulueta narrates the desire of a group of young people to disrupt the "Song Festival of MundoCanal" (a Eurovision parody). To do this, he surrounds himself with musical performances by the main bands of the Spanish "modernity" of the moment, such as Los Angeles or Formula V, among others. The film shows, beyond the alternative music of the time, images, gestures and dialogues that help us find the defining lines of what we can call underground culture during the Franco regime. In this article we try to deepen the meaning of some of these dialogues (mostly jocular), as well as the image that is offered of the different musical formations and the characters of the story, to recognize the countercultural attitudes that marked a culture submitted by a hegemonic ideology, the Francoist, in a city in which little could be expected the development of a counterculture, as was Madrid.
\end{abstract}

Palabras clave:

Contracultura; cultura underground; franquismo; 1,2,3 al escondite inglés; Iván Zulueta.

Keywords:

Counterculture; Underground Culture; Francoism; 1,2,3 al escondite inglés; Iván Zulueta. 


\section{Introducción}

Lo que más llama la atención del filme 1,2,3, al escondite inglés de Iván Zulueta es la imagen colorida y psicodélica que se ofrece del Madrid de los años 70, algo que ya comentaron José Roberto Vila Oblitas, Vanesa Francisca Guzmán Parra en 1, 2, 3, al escondite inglés, la locura pop de Iván Zulueta (2011). Sin embargo, sus diálogos, aunque cortos y en su mayoría escasos -dejando la acción y el principal leitmotiv de la película en los números musicales de las bandas del momento-, muestran una serie de actitudes y datos (la mayoría, difíciles de ser clasificados a simple vista) capaces de representar la cultura underground durante la dictadura franquista.

No podemos olvidar que, a pesar de la imagen alegre y psicodélica que ofrece esta película de la España de 1970, en aquel año todavía se mantenía la censura, así como la Ley del Orden Público (1968), la Ley de Prensa (1970) y la de Vagos y Maleantes (reformada en 1970); leyes que coartan el desarrollo de una cultura underground. De hecho, como comentaremos más adelante, en 1971 encontramos el récord (F. Neira) de canciones censuradas en la radiofórmula, 701 temas de los 4.00o que se censuraron durante la dictadura.

Pocos años antes, en 1966, la visita de los Beatles a Las Ventas de Madrid se había saldado con revueltas y cargas policiales entre los jóvenes que, aun habiendo comprado la entrada para el evento, no habían podido pasar por no haber lucido de manera "ideal", un adjetivo que veremos utilizado a lo largo de la película de Zulueta. Los "melenudos", denominados así por la prensa del momento, no estaban bien vistos, e incluso un conjunto pop tan aparentemente inofensivo como el cuarteto de Liverpool era susceptible de atraer a personajes que al Régimen no le gustaban, y que agrupaba en el texto de ley con homosexuales, maleantes, gente de mal vivir... como podemos ver a continuación de la mano de Pablo Carmona:

Esta nueva legislación fue la Ley de Peligrosidad Social, aprobada el 6 de agosto de 1970. La Ley de Peligrosidad Social fijaba su atención sobre todas aquellas formas sociales crecidas al abrigo de los bares, la vida nocturna o los territorios ocultos de las comunidades marginales que recorrían a contracorriente calles y plazas. En concreto, con esta ley eran perseguidos: homosexuales, pornógrafos, mendigos, ebrios, toxicómanos, gente que posea drogas, personas con comportamientos 
insolentes, cínicos o brutales, jóvenes pandilleros o pertenecientes a bandas, menores (de 21 años) rebeldes o moralmente pervertidos, emigrantes clandestinos, prostitutas y maleantes. Enfermos y deficientes mentales, delincuentes con más de tres delitos, además de otros muchos subtipos y caracterizaciones que debían ser tratados con toda severidad por medio de "medidas de seguridad" que les castigase, confinase y rehabilitase en establecimientos especiales. (2012, p. 252)

Pablo Carmona termina resumiendo que los personajes anteriormente descritos podrían encontrarse juntos, muy probablemente, en un "día normal en la Plaza Real de Barcelona” (2012, p.252), así como también una actitud clara de ir a la contra. En este texto viene a resumirse una contracultura, una actitud de ruptura con lo establecido, empezando con la vida familiar. Aunque de eso hablaremos más tarde, a tenor de la "palabra e imagen” que ofrece Zulueta en su largometraje. Una situación de la que incluso Paul McCartney se dio cuenta dentro de La Ventas de Madrid, un hecho que Ramis Plomer explica en este texto:

El público no llegó a llenar la plaza de toros de Las Ventas de Madrid el 2 de julio (...) había mucha más gente fuera que dentro, y unos años más tarde, Paul McCartney diría en una rueda de prensa que no les gustó demasiado el concierto. "Los de dentro eran los ricos. Los de fuera, los pobres. Nos hubiera gustado tocar para ellos". Algunas personas sostienen que aunque habían comprado la entrada, no las habían dejado entrar. Otras, que tan solo se habían acercado a la plaza de toros por si los veían entrar. En las dos ciudades hubo cargas policiales cuando los conciertos terminaron a causa de la gran concentración de gente. (2014, p. 35).

En cuestión de cinematografía, sin embargo, el Régimen parecía pretender una apertura que acercara a los jóvenes artistas a la industria del cine español ${ }^{1}$. La Escuela Oficial de Cinematografía, donde coincidieron Iván Zulueta y José Luis Borau, se convertía en estos años (finales de la década de los 60) en el punto de encuentro que motivó gran parte de los avances del Nuevo Cine Español. Virginia Sánchez Rodríguez explica en el siguiente texto las líneas definitorias de la EOC:

El Nuevo Cine español surgió en torno a la Escuela Oficial de Cinematografía. A pesar de su carácter vanguardista, cuajó en la sociedad española y fue el beneficiario de gran parte de las subvenciones otorgadas por el Estado. Este

\footnotetext{
1 "Pero la nueva política diseñada por José María García Escudero desde la Dirección General de Cinematografía quería aumentar la producción de cine en España y favorecer la entrada de gente joven a la industria. En definitiva, nuevos aires y nuevos directores en un contexto que, aparentemente, perseguía un nuevo camino, al menos de cara a la galería” (Rodríguez, V. S. 2014. p.74).
} 
término agrupaba un colectivo heterogéneo de creadores llegados desde toda España y abarca a Basilio Martín Patino, Mario Camus, Pedro Olea, Antonio Eceiza, Julio Diamante, Miguel Picazo, Manuel Summers, José Luis Borau, Antonio Mercero y Víctor Erice, entre otros. A pesar de sus divergencias estilísticas, todos ellos compartían un afán crítico por contar la realidad y replantear cuestiones como la familia, la pobreza, las convenciones sociales o la falta de libertad. (2014, p. 76).

Encontramos enumerados aquí a personajes que pasarían a formar parte de la historia del cine español. El mismo José Luis Borau llegaría a ser Presidente de la Academia de Cine entre 1994 y 1998. Sin embargo, en los momentos de rodaje de 1,2,3, al escondite inglés, primera película producida por El Imán² (productora creada por Borau) casi podemos llegar a contemplar un primer ejercicio de cine, que hizo aguas en cuanto a producción (inclumplimiento de días y horarios de rodaje, apareciendo Zulueta horas más tarde de lo que marcaba la hora de inicio), distribución (apenas se llegó a estrenar en dos salas de arte y ensayo en Madrid y otra en Barcelona) y guion (que se iba desarrollando sobre la marcha)3.

Es por esto que, en la película, por muy aperturista y moderna que pueda parecer, los diálogos que desvelan el funcionamiento de una contracultura son escasos. También aquellos que permiten cuestionarnos el estado dictatorial que se vivía. No podemos olvidar el estado hegemónico en el que nos encontramos en 1970, así como tampoco el doble estado de castigo que se vivía en Madrid, ciudad que había pasado de ser la creadora de ese grito tan poderoso "No pasarán”, durante la Guerra Civil, a ser la capital de una España que se definía por "una, grande y libre”. Y, por supuesto, centrista.

Esta es la razón por la que las palabras en las que encontramos pequeñas pistas sobre la contracultura madrileña durante el Franquismo, han de ser buscadas en la película de Zulueta entre broma y broma y entre imágenes que tratan de tapar

\footnotetext{
2 Productora de José Luis Borau. 1,2,3 al escondite inglés fue su primera película, enmarcada dentro de las líneas definitorias de la EOC. Iván Zulueta tuvo problemas para firmar como director de la película en un primer momento, al no disponer de carnet sindical de la profesión, que se podía conseguir siendo alumno de la EOC, un requisito que Zulueta no cumplía. Así, tuvo que intercambiar roles con Borau, quien pasaba a denominarse como director. El trabajo de El Imán fue gestionar el bajo presupuesto, que provocó que la mayoría de las escenas musicales se desarrollan en exteriores y que los grupos cedieran su imagen de manera gratuita. El mismo Zulueta pintó los decorados del fikme (la tienda de discos, etc.).

3 Datos extraídos de la biografía oficial de José Luis Borau en la SGAE: http://www.sgae.es/recursos/especiales/2011/borau/biografia.html
} 
cualquier atisbo de actitud rebelde con color, trucos de cámara y edición psicodélicos y grandes dosis de creatividad e incluso banalidad. Estas palabras y diálogos que podrían parecer jocosos (y de hecho, lo son), descubren un modo de vivir la cultura underground que sería precursora de la archiconocida Movida Madrileña.

\section{Objetivos, hipótesis y metodología}

El objetivo principal de este artículo es rescatar las conductas y actitudes que definen a la cultura underground madrileña durante la dictadura franquista a través de una selección de palabras e imágenes de la película 1,2,3 al escondite inglés de Iván Zulueta (1970).

Con ello pretendemos demostrar, como objetivos secundarios, que existía una contracultura en Madrid durante el periodo dictatorial que utilizaba la música en directo como hilo conductor de patrones de conducta y actitud frente a la cultura hegemónica; así como una clara distinción entre la cultura juvenil y la cultura normativa representada por la dictadura.

Para ello, partimos de la hipótesis de que la película 1,2,3, al escondite inglés, muestra a través de sus palabras e imágenes patrones de conducta contraculturales que evidencian la actitud de la cultura underground madrileña durante el Franquismo.

Para demostrar esta hipótesis y llevar a cabo los objetivos de la investigación, se empleará el análisis de contenido como metodología. Se trata de un análisis de contenido que parte de un universo que abarca la totalidad de la terminología de los diálogos de esta película. A partir de ahí se ha seleccionado una muestra de seis diálogos que consideramos representativos de la cultura underground durante el Franquismo. Estas se analizarán junto a los rasgos que las definen.

Cada una de las secciones del artículo estará encabezada por alguno de estos diálogos. A continuación, explicaremos qué situación se esconde detrás del humor de estas palabras y lo relacionamos con la contracultura de aquella época. Asimismo, realizaremos un análisis de la imagen que acompaña a cada diálogo. Se tendrán en cuenta factores como el color, la estética de los planos, el vestuario de los actores y la luz y efectos visuales que tienen lugar dentro de la escena en la 
que encontramos los diálogos a tener en cuenta. Analizar la imagen en conjunto con las palabras que rescatamos de cada secuencia permite contextualizar el diálogo, así como captar actitudes y ambientes que pasan desapercibidos con el simple análisis textual del guion. Para ello, elegimos una muestra de seis imágenes que acompañan narrativamente a los textos analizados.

\section{Palabras e imágenes de 1,2,3, al escondite inglés}

\section{1. "Una canción moderna, pero melódica"4}

La película comienza con unos breves y psicodélicos, aunque grisáceos, títulos de crédito. Se trata solo de un primer rótulo que muestra el nombre de la productora (El Imán), bajo un fondo negro y una tipografía que ahora podríamos denominar como "setentera". Estos títulos anticipan la primera parte del filme, una secuencia introductoria en la que veremos representados a los personajes que explicarán qué es el Festival de MundoCanal y de qué manera se desarrolla.

Esta secuencia que sirve como introducción de la película, se rueda al estilo de una retransmisión televisiva (desde lo que parecen ser los escenarios de Prado del Rey de Televisión Española, único canal de la época), desde dentro, sacando en imagen a los realizadores, cámaras y televisores en los que vemos cómo queda la imagen que se proyecta en las casas. En este momento, un presentador vestido de un modo distinguido, con ademanes caballeros, según los cánones mainstream de la época (traje elegante, bigotillo fino y habla afectada y engolada) presenta a los telespectadores a la compositora del tema que representará a España en el Festival de la Canción de MundoCanal, titulada "Mentira, mentira".

Rodríguez resume la jocosidad de esta secuencia introductoria en su texto sobre la influencia de la canción popular:

1,2,3 al escondite inglés es una película con canciones, alejada de los postulados del Régimen, de estilo poco convencional y de estética psicodélica. La música original del film, compuesta por Pérez Olea, presenta una convivencia de algunos de los conjuntos musicales de la época más conocidos, de diferentes estilos, como Los Ángeles, Los Pop Tops, Los Beta, Los Buenos, Fórmula V, Henry y los Seven, Los Íberos, Los Mitos, Shelley y Nueva Generación, The End y el cantautor castellano

\footnotetext{
4 Minuto 0.56 del metraje.
} 
y leonés Ismael. Pero en la muestra también se realiza una crítica hacia los festivales de canción contemporánea que tanto éxito tenían en la época y que incluso hoy en día perviven. La considerada "pantomima" hacia los concursos europeos e hispanoamericanos se materializa a través del personaje femenino que presenta la canción para ir a Eurovisión: “Mentira, mentira”, participación que trata de boicotear un grupo de amigos. (2014. p. 530).

El tema, o la "pantomima” a la que se refiere Virginia Sánchez Rodríguez en este texto, se califica como "una canción moderna, pero melódica”. Es en esta primera frase, consistente en una dicotomía “algo, pero otra cosa”, donde se encuentra una de las claves con las que pasaremos a desgranar la cultura underground madrileña durante el Franquismo.

En la dicotomía "moderna, pero melódica" localizamos una contradicción que no cabe en los planteamientos de los protagonistas de la cinta de Zulueta: lo moderno, para ellos, huye de la tradición melódica de la canción española. En unos años en los que Raphael copa la popularidad de los cantantes del momento y se convierte en el rostro permitido del Régimen, la cultura underground, definida por "ir a la contra" de aquello que está impuesto o aceptado, no puede sino dirigirse por el camino contrario a lo "melódico". Un camino marcado por los grupos y bandas internacionales que empezaron a escucharse en España gracias al aparente aperturismo y la entrada del turismo de la era Desarrollista del Franquismo (1969-1975). Paloma Otaola lo resume de la siguiente manera:

Como en EEUU, en Inglaterra y en Francia, también en España nació una conciencia de grupo entre los jóvenes al calor de los ídolos musicales. Con palabras de José María Iñigo "la música y la moda fueron claves para que España compartiera la modernidad en la que llevaba ya instalada unos años antes el resto de Europa occidental. Si política y económicamente España avanzaba con retraso, en música estuvimos a la última desde el primer momento”. (2012, p. 31).

Como se aprecia a lo largo de esta producción, lo moderno pasa, gracias a las formaciones grabadas a modo de protovideoclip, como Shelley y la Nueva Generación, Los Buenos, etc., por cantar en inglés y adoptar las actitudes que trae consigo aquel Mayo del 68 si nos referimos a Europa, o bien el movimiento hippie en los EE.UU.

Actitudes que pasan por una estética colorida que contrasta a lo largo de la película con el negro riguroso con el que viste Obregón, compositora del tema "de 
marras", como se menciona en el diálogo, (o bien las viejitas a las que uno de los jóvenes protagonistas embauca para conseguir el nombre del conjunto que asistirá a MundoCanal).

El negro de Obregón y las viejitas contrasta con los coloridos y originales trajes que viste la modernidad, representada por los personajes principales y los conjuntos musicales. En el caso de Formula V, también se observan similitudes en el peinado y la vestimenta a Los Beatles. En general, se aprecian peinados más salvajes y melenudos y una actitud lánguida y hedonista.

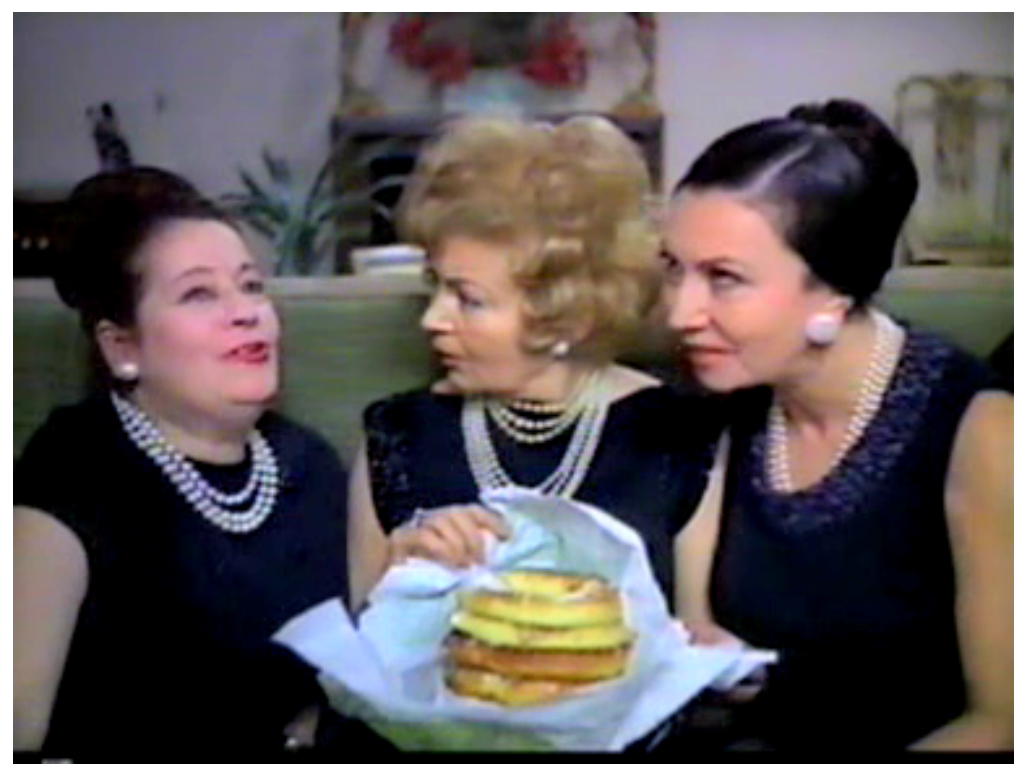

F.1. Las viejitas, vestidas de negro y con perlas, que resultan embaucadas por uno de los jóvenes protagonistas. (Minuto 45).

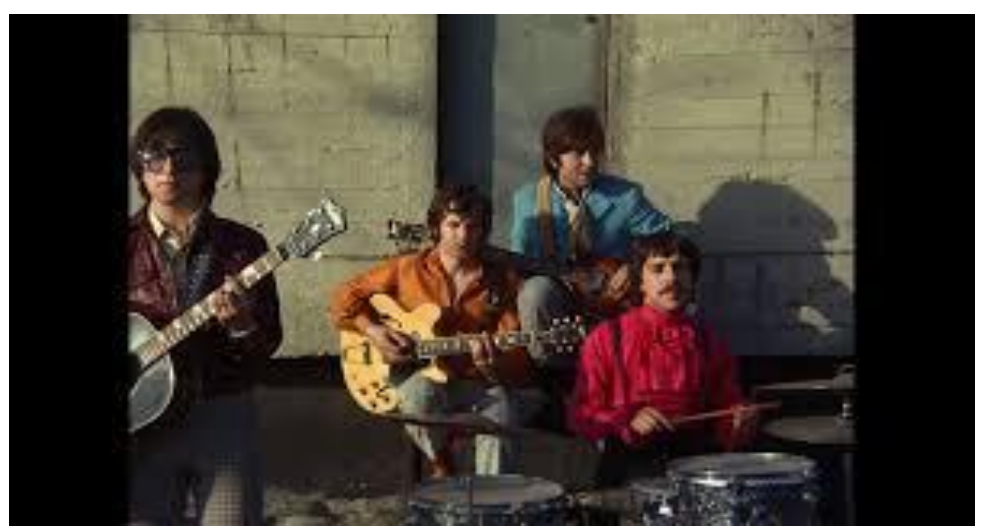

F.2. Grupo The End en 1,2,3 al escondite inglés. El color de la modernidad frente al blanco y negro de la generación precedente.

Volviendo a "Mentira, mentira", en su composición encontramos también trazas de la copla que extasió a los españoles durante la posguerra y la primera década de los 70, siendo la música más a gusto del Régimen, como explica Paloma Otaola: 
Es bien conocido el gusto de Franco por la copla y la canción española que contribuía a reforzar el sentimiento nacional español. Cada año, en la conmemoración del 18 de Julio, las estrellas del momento como Conchita Piquer, Juanita Reina, Lola Flores, Antonio Amaya, Antonio Molina etc. eran invitadas a interpretar las canciones favoritas del Generalísimo. (2015, p.31).

¿Cómo podrían aceptar, entonces, los protagonistas de 1,2,3 al escondite inglés, un tema que no sigue la moda del momento, sino que regresa a la que adoraron sus padres? Una canción que no responde a su noción de modernidad, ya que se trata de un tema cantado en español, que mantiene la estética normativa (líneas rectas, color negro, pelo recogido...) y contiene un regusto a copla. Los protagonistas se sienten heridos al escuchar esta canción, que aunque ahora nos podría parecer una canción sin más, en aquel momento debemos comprender por oposición. La contracultura rechaza las culturas paternales, así como las hegemónicas. La contracultura, por tanto, rechaza un tema que no va a la contra y que resulta "ideal" para aquellos que mantienen el orden y la cultura impuesta, como veremos a continuación.

\section{2. "Conjunto ideal" 5}

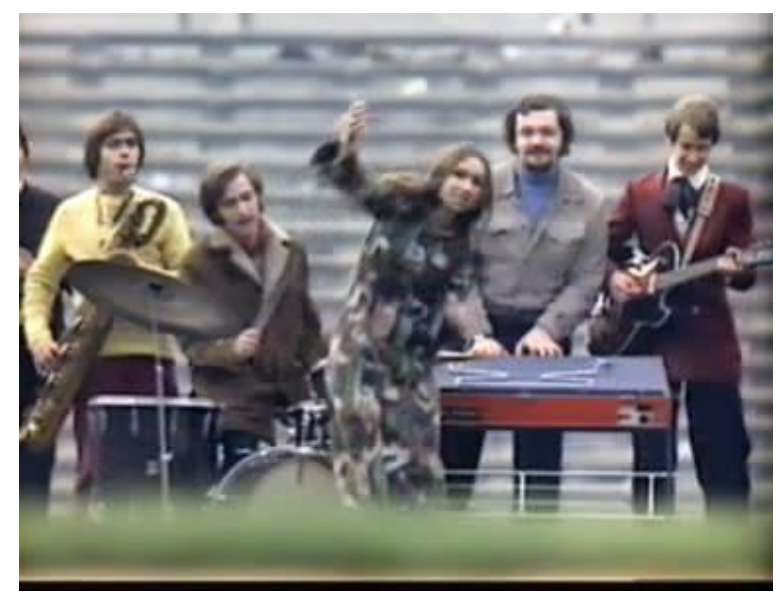

F.3. Shelley y la nueva generación en 1,2,3, al escondite inglés.

Al preguntarle el presentador a Obregón, compositora del tema, a quién ve interpretándolo para el Festival de la Canción de MundoCanal, ella responde diplomáticamente que hay muchas formaciones en España que podrían llevarlo a cabo sin problemas. El presentador la empuja levemente a modo de broma, y hace referencia a ese "conjunto ideal” capaz de llevar a cabo la interpretación del

\footnotetext{
5 Minuto 1,05 del metraje.
} 
tema elegido. Con ese "conjunto ideal" volvemos a encontrarnos con las expectativas del régimen versus las expectativas de la juventud española del momento.

Es en este momento cuando se inserta la premisa de la película: el Régimen, representado a través de los "seleccionadores" mencionados por el Presentador al final de la secuencia de introducción, trata de convencer a formaciones musicales juveniles y modernas de la época para que "se presten" (expresión que se estudiará más adelante, en el punto 3.3) a interpretar un tema que no resulta ni moderno ni juvenil, y que es definido por uno de los personajes protagonistas de este modo: “iQué cursi! iQué reaccionario! iQué pasado de moda! iQué vergüenza! iQué mal!”.

Aunque pueda resultar una premisa poco creíble, lo cierto es que en 1968 el artista seleccionado para participar en el Festival de Eurovisión fue el cantautor Joan Manuel Serrat, quien rechazó el encargo de cantar "La, la, la" por no poder hacerlo en catalán. El encargo cayó entonces en manos de Massiel, una de las cantantes de moda del momento. Si no resultó inverosímil para los seleccionadores del Festival de Eurovisión proponer a Serrat, un cantautor que seguía las líneas de actitud contraculturales, entonces no debería parecernos increíble la premisa de la que parte esta película.

En esta línea argumental se observa de manera clara una oposición a las expectativas del Régimen: los protagonistas se oponen a que bandas musicales modernas (en este punto podríamos decir "contraculturales", o "underground") acepten interpretar un tema que ha sido compuesto según todos los cánones de la normatividad del momento.

¿Cómo expresar, entonces, la disconformidad de la juventud, en una sociedad sin libertad de expresión? La actitud de ir a la contra encuentra un modo de representación en los hábitos de consumo de los jóvenes: no vestir como sus padres, no escuchar aquello que escuchaban sus padres, mantener una actitud distinta a la que se muestra como normativa. De nuevo, Paloma Otaola nos resume el papel de la música como contraria al adjetivo de "ideal" que remarca el presentador de 1,2,3, al escondite inglés:

Su rápida expansión y su puesto cada vez mayor en la vida de los jóvenes hicieron de la música el cauce privilegiado de expresión de la juventud, contribuyendo a 
crear, como en los demás países occidentales, la conciencia de la identidad "joven" frente a la sociedad adulta. Esta identidad joven, abierta a las modas extranjeras, irá cobrando fuerza a lo largo de la década, manifestándose no sólo a través de la música, sino también en la forma de vestir, en nuevas formas de divertirse y en definitiva dando lugar a cambios de mentalidad que serán patentes en la década siguiente. (2012, p. 62).

Otro aspecto a tratar es el consumo, un área que tampoco escapa del sistema hegemónico, encauzado a través de la publicidad televisiva que se inserta en la película: "Soy la madre de los Beatles", comienza un anuncio -es, evidentemente, un gag-. El Régimen rechaza a los Beatles, pero trata de fagocitarlos cuando se trata de arrastrar a este sector de la juventud a su propio terreno.

Esta resistencia se aprecia también en el snobismo del que hacen gala los personajes principales: “Aquí solo vendemos auténtica música pop”, manifiesta la encargada de la tienda de discos (Judy) a una clienta, en el minuto seis. Se trata de una resistencia que, a falta de un hilo conductor, se materializa en sectarismo, en un "nosotros no somos como ellos". Es decir, "nosotros no somos ideales". José Olmo Cano se refiere también a este aspecto a la hora de abordar una película necesariamente precursora de 1,2,3, al escondite inglés, el musical Megatón Yeyé de Jesús Yagüe (1965):

En España, los adolescentes también quisieron seguir el modelo británico, sentirse jóvenes, libres, diferentes con respecto a sus mayores, y disfrutar de las formas culturales de ocio y de una moda que los equiparaba a la juventud europea que veían en las revistas juveniles (Ondas, Discóbolo, Fonorama, Fans y Mundo Joven, entre otras) y en los programas de televisión (Escala en Hi-Fi, Cancionero y Sonría, por favor). Como vemos, ante este panorama, y en relación con lo dicho en párrafos precedentes, la intención del régimen de mantener unas costumbres y unos valores tradicionales propios de la nación, distaba mucho de la realidad sociocultural que se vivía en aquellos años del "desarrollismo"." (2015, p. 47).

Este cambio en el modelo de consumo, así como la oposición y la disconformidad de los jóvenes de la época con las generaciones paternas, se puede encontrar representado también en la imagen que esta primera secuencia de 1,2,3, al escondite inglés nos muestra, tanto de los jóvenes, como de la sociedad normativa que podemos ver por televisión (controlada, también, por el Régimen). Como ya se ha mencionado al comienzo de este punto, la sociedad normativa se materializa 
en los personajes de Marina de Obregón (compositora de la canción "Mentira, mentira") y el presentador que se encarga de introducir la noticia relacionada con el Festival de MundoCanal. Estos personajes los encontramos en un fondo gris, con un piano negro, vestidos ambos de blanco y negro. No hay color ni alegría en sus expresiones, tan solo una sonrisa engolada a cargo del presentador.

Esta secuencia introductoria termina con unos títulos de crédito coloridos y psicodélicos, en tonos flúor, que van apareciendo en pantalla a través de animaciones y con letras (al igual que la del primer rótulo), de corte hippie "setentero". Esta locura de color y música moderna como fondo, de corte funk, nos lleva a la primera secuencia de la cinta, en la que los protagonistas principales aparecen reunidos en la tienda de discos que les sirve de refugio (y cuyo casero, un niño mimado, arquetipo de los "hijos de papá" que poblaban los sectores privilegiados de la dictadura franquista, no cesa en su empeño de subirles el alquiler).

La tienda es introducida en imagen con un primer plano de los vinilos (coloridos, alegres, modernos, de los Beatles, los Bee Gees, la banda sonora del musical Hair...) que allí se venden. Se puede contemplar una pared negra y roja, y al final de los estantes, al personaje de Antonio pintando el mural de una mujer (color rosa) en la pared. Judy, la encargada de la tienda, le pide que le dé la vuelta al disco que estaba sonando. Ambos van vestidos con colores vivos (él, con una camisa azul de lunares y un sombrero, ella con un pañuelo rojo, también de lunares, y un corte de pelo a lo garçon muy alejado del recatado recogido de Marina de Obregón).

En esta introducción se distingue el contraste entre el mundo moderno y el mundo antiguo. Una vez presentados los personajes, nos disponemos a entrar en el primer acto, en la carrera de los jóvenes por boicotear el Festival de la Canción de MundoCanal con una frase que resume todos sus motivos:

\section{3. “¿Pero cómo pueden prestarse?” 6}

La pronuncian al saberse que serán Los Buenos los que acepten asistir al Festival, cantando el tema que han elegido para ellos. Es aquí cuando comienza el primero de los videoclips de la película (si obviamos la pequeña introducción cantada de

\footnotetext{
${ }^{6}$ Minuto 9, 11 del metraje.
} 
Obregón interpretando "Mentira, mentira", de manera afectada y apasionada, lejos de las actitudes lánguidas de los modernos). En Los Buenos vemos las camisas psicodélicas, los pelos largos, el cante en inglés y el hedonismo pasota de "todo me da igual" que refleja una actuación hecha casi para sí mismos, en una especie de salón de grabaciones.

A la hora de preguntarles si serán ellos (Los Buenos) los que asistan al Festival, ellos niegan con una frase que pretende ser cómica: "Qué va, ¿no ves que estamos haciendo la mili?”

Si retomamos el verbo "prestarse", hallamos que los conjuntos musicales que no tienen nada que ver con el Festival salen impunes, mientras que aquellos que sí han aceptado "prestarse" a cantar un tema normativo y a gusto del Sistema son liquidados, o "puestos fuera de combate" (como se expresa en la película) gracias a unos globos venenosos encontrados en la casa de una de las tías de las protagonistas. Se trata de una de las secuencias más psicodélicas del metraje, en la que se muestran los colores invertidos y un divertido uso del sonido para representar a los malignos globos.

En la actualidad, casi se podría decir que el verbo “prestarse” podría ser sinónimo del popular "venderse". Un pecado capital dentro de la cultura underground, que ha de mantenerse intacta y ajena a las convenciones sociales. No por esnobismo, sino por protección frente a un sistema que, incluso en la actualidad, es capaz de fagocitar las actitudes de moda, normalmente contraculturales, para hacerlas formar parte de su registro, de tal forma que no haya escapatoria posible a la normatividad. En la siguiente cita, Cano explica cómo se produjo esta fagocitación del espíritu rebelde, seña de identidad de la música moderna, por parte de la prensa y los medios:

Pero no era esta una mera cuestión de gusto y moda. Este quehacer musical vino asimismo derivado por una suerte de nacionalismo que, fundamentalmente desde la prensa, abogaba por una música moderna española, apoyada, principalmente, por el sello Novola, división de Zafiro para el impulso de la música moderna española destinada a un público joven (Alonso 2010: 221), y por la revista musical Fonorama, creada a partir del mismo propósito. (2015. p. 56).

A propósito de los medios de comunicación se encuentra el siguiente diálogo, pronunciado en el coche que comparten los protagonistas. Al saber que no serán 
Los Buenos los que representen a España en el Festival, los jóvenes buscan en la prensa una pista que les lleve al conjunto elegido e "ideal”.

\section{4. "Se prohíbe la portada de los Rolling, se prohíbe la portada de... desde ahora los discos irán sin funda. La última película de los Beatles es un fracaso... iTodo mentiras!"7}

A la hora de describir a la modernidad, la prensa del Régimen no tenía reparos en denominar a los fans de los Beatles como "melenudos" y demás adjetivos denigrantes ${ }^{8}$. Tampoco escatimaba en adjetivos y presunciones de culpabilidad para los jóvenes que concurrían, años antes, a las Matinales realizadas en el Circo Price de Madrid 9 , que terminaron de forma abrupta por denuncias de vandalismo entre los jóvenes que asistían. Parecía, entonces, no tenerse en cuenta los actos violentos sucedidos en eventos deportivos o corridas de toros, sino que tan sólo resultaban peligrosos los desarrollados en actos de música popular. Paloma Otaola recoge la situación de las Matinales en la prensa en el siguiente texto:

(...) se formaban grandes colas para comprar las entradas con anticipación (Iñigo, 2004, p. 41). Durante la primera temporada 1962-1963 se organizaron 13 festivales. (...) Comenzaron a aparecer en la prensa comentarios negativos sobre los chicos y chicas que salían por la calle bailando y aullando al ritmo enloquecido del Twist. La música moderna era vista por la sociedad de adultos como patear, berrear y hacer ruido (Pardo, 1988, p. 32). La revista Triunfo (27, 8 de diciembre de 1962) hizo un reportaje sobre los conciertos del Price (...) Se subraya el frenesí por la música moderna y la actitud similar de los jóvenes españoles a la de los extranjeros (...) Aunque el tono del reportaje traduce el asombro, no sin cierta ironía, ante el entusiasmo de los jóvenes comparable con la afición al fútbol, se puede leer entre líneas una cierta crítica ante las manifestaciones desenfrenadas” (2012, p. 35).

La prensa consideraba a los jóvenes modernos como vándalos, mientras la censura hacía lo propio, como ya comentamos al inicio de este artículo, con 701 canciones sin permiso para ser radiadas, tan sólo en 1971. Se censuraban también

\footnotetext{
7 Minuto 14,22 del metraje.

8 "Había que echarle valor para enfrentarse a extensos sectores de la prensa y la sociedad que tildaban a los músicos británicos poco menos que de 'degenerados', 'elementos disolventes' e incluso 'afeminados'. También los motejaban de 'escarabajos', confundiendo, a causa de que la pronunciación es la misma, 'beatles' con 'beetles'”. (Carlos, T. 2015, p. 2).

9 Festival urbano de música ye-yé organizado en el Teatro Circo Price de Madrid en horario matinal desde 1962 a 1964.
} 
portadas, hasta el punto de afirmar (a modo de gag dentro de la película), que "los discos irán sin funda”, una frase pronunciada por Judy que denota su hartazgo con respecto a la prensa, un chascarrillo que acompaña al diálogo que da título a este epígrafe.

La acción tiene lugar en el pequeño coche gris en el que los protagonistas de la película deciden emprender trayecto para encontrar a las distintas formaciones musicales que actúan durante el metraje. Al conocer que no serán Los Buenos los que participen en el Festival de la Canción de MundoCanal, Judy coge un periódico y empieza a leer los titulares de la sección de Música en busca de alguna pista que les haga conocer qué grupo será el elegido. El resto de sus compañeros se aburre abiertamente mientras ella se indigna con las noticias, aparentemente poco fiables, que se encuentra en las páginas.

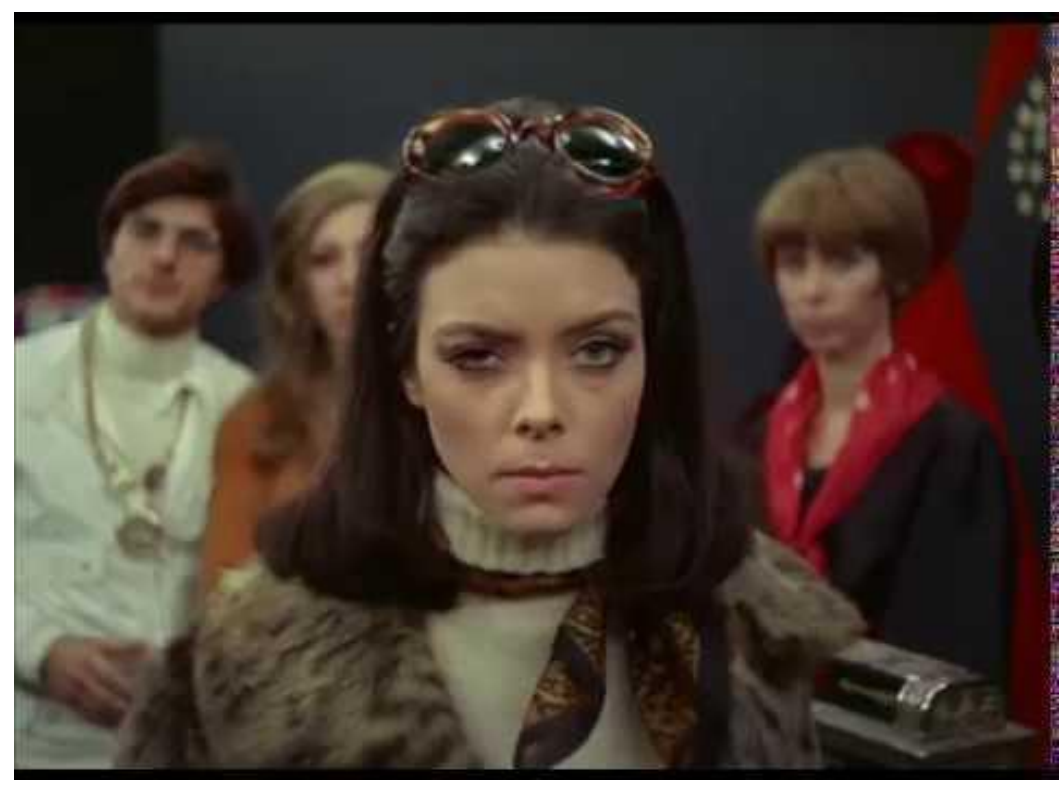

F.4. El personaje de Patti (Patti Shepard), en 1,2,3, al escondite inglés.

Sigue el metraje, y Patti (interpretada por Patti Shepard), la actriz y modelo del grupo de amigos, se dirige a una tienda para comprar un póster de Verónica Lake, encontrándose con José María Iñigo, dando lugar a una de las frases más divertidas de la película: "Yo tengo unos discos horribles gracias a ti". En esta frase se advierte una pequeña crítica a José María Iñigo, un personaje que, dentro de la película, representa al selector de las canciones que los protagonistas odian, por los motivos que se han explicado anteriormente (punto 2.3.) 


\section{5. "Pues a mí me gusta, es una canción muy bonita”, Pero, ¿cómo puede gustarte?, En el cuartel se vuelve uno tan romántico... ${ }^{10}$}

En este comentario pronunciado tras la conversación con José María Iñigo, y tras haber acabado con Shelley y la Nueva Generación de un pelotazo en la cabeza de Shelley, se contempla una nueva referencia al servicio militar obligatorio, que ya encontrábamos en boca de Los Buenos. Otra de las herramientas del sistema para mantener a los jóvenes (esta vez, siempre en masculino plural) a raya.

En este diálogo se alude al modo que el Sistema tiene de intentar devolver a los jóvenes al redil: el chiste que contiene este diálogo es que la mili puede acabar haciendo que incluso pudiera gustarte "Mentira, mentira". La mili puede acabar convirtiéndote en una persona normativa. Esta frase será respondida por otro de los personajes, que señala “a mí es que el amateurismo me saca de quicio”. El resto de personajes se miran entre ellos y asienten con la cabeza sin demasiada convicción. Se trata, de nuevo, de otra broma solo comprendida en el ámbito de la contracultura, donde la mayor parte de las bandas son amateur y no cuentan con una formación clásica.

Se trata, a fin de cuentas, de jóvenes abrazando una cultura que se aleja de lo paternal y lo normativo, sepan o no cómo funcionan las guitarras que sostienen. De dejarse llevar por la ciudad que recorren los personajes de Zulueta en una espiral que les aleja de las normas y valores convencionales.

De nuevo, podemos observar esta confrontación de lo antiguo y lo moderno, que parece repetirse a lo largo de toda la película, en la secuencia que da paso al diálogo con el que comenzábamos este epígrafe (2.4). De nuevo, volvemos al punto en el que Patti se encuentra con José María Iñigo. El inicio de esta secuencia $^{11}$ es un primer plano que recorre las paredes de una tienda de discos, diferente al refugio de los protagonistas. En esta ocasión, las paredes están forradas con posters en blanco y negro que muestran a representantes de la cultura popular (todos ellos, varones). Al terminar este plano, nos encontramos con el personaje de Patti, que trata de preguntar a un dependiente, aunque sin éxito. De fondo, en la pared, más fotos en blanco y negro. Patti sigue avanzando, y pasa de la habitación forrada con pósteres a una nueva estancia colorida (en 
tonos amarillos, a juego con la boina que viste Patti), en la que ella se dirige a Iñigo. En esta estancia hay discos. La música elimina el blanco y negro de un pasado (que podemos ver representado en el personaje del dependiente) que no reacciona ante las palabras de la juventud (Patti). Mientras, la sección de música se distingue por su color, alegría, y alguien a quien dirigirse (Iñigo).

\section{6. “¿No te da vergüenza, mamá? En cuanto te dejan sola te pones a hacer psicodelia" 12}

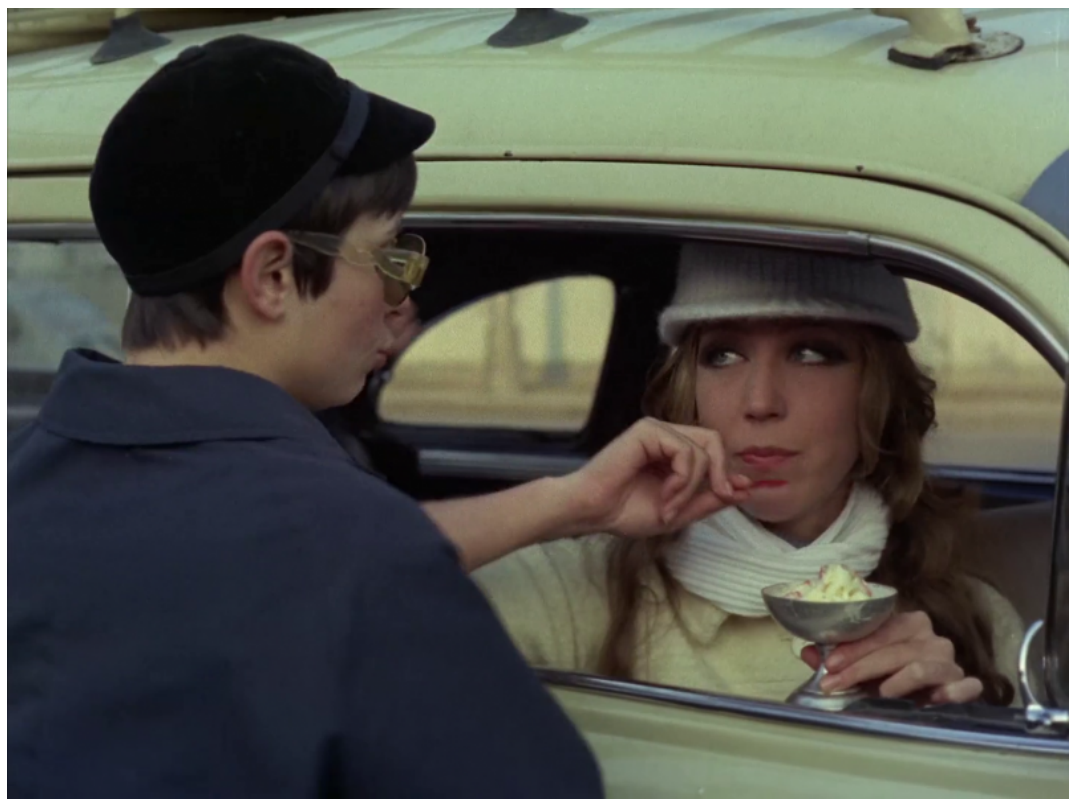

F.5. Tina (Tina Sáinz), con boina y gafas psicodélicas, en 1,2,3, al escondite inglés.

Tina (interpretada por Tina Sáinz), un personaje que imita a Lina Morgan en su actitud de pueblerina recién llegada a la ciudad, es descubierta por su hijo pequeño tras haber acabado con la enésima banda dispuesta a participar en el Festival de MundoCanal. De este modo, un personaje que no llegamos a saber muy bien en ningún momento por qué está ahí, es reconocido como otro de esos seres que escapan de la esclavitud social, convencional y normativa de un pueblo pequeño para entregarse a la libertad que supone el anonimato dentro de una gran ciudad. Bruno Lutz resume este concepto a la hora de articular su concepción del cuerpo y el espacio, partiendo de los estudios de David Le Breton:

David Le Breton afirma, con razón, que el desarrollo de la ciudad tuvo una consecuencia significativa sobre los usos y las representaciones sociales. La socialización proxémica de las urbes impuso sus reglas: la de ver sin mirar con el

12 Minuto 1,02,10 del metraje. 
uso masivo de cristales polarizados, la del oír sin escuchar con el ruido de los automóviles, la de oler sin olfatear a causa de la contaminación. El diseño de las ciudades y de los espacios públicos ha provocado una reducción notable de la capacidad de los sentidos para comprender el mundo que nos rodea, limitando nuestras percepciones y apreciaciones de los demás. (2006, p.15).

Una mujer, en el campo, pertenece siempre a los demás: es la "hija de", la "madre de"; algo que en los hombres también se abrevia con el consabido "tú eres el de...", seguido del apodo familiar, conocido dentro del pueblo. En la ciudad, Tina deja de ser madre para ser agente contracultural con capacidad de acción, ya que nadie conoce su pasado ni su identidad.

El inicio y el final del recorrido de este personaje podemos verlo a través de tres secuencias: la primera, en la que Tina se acerca corriendo a uno de los protagonistas, el personaje de Ramón (interpretado por Ramón Pons); la segunda, el momento que sigue al número musical de los protagonistas parodiando un cabaret, en el que Tina, vestida al estilo oriental, empieza a caer en la psicodelia (punto de inflexión de la narrativa del personaje); y el tercero, el instante con el que comenzábamos este punto (2.5), en el que Tina es descubierta como madre. Tras exponer las palabras de esta secuencia nos adentramos en sus imágenes.

En la presentación de Tina, observamos a un personaje vestido de manera oscura, con una gorra y un abrigo azul marino, lanzándose con una maleta a preguntarle a Ramón: “disculpe, señor, ¿usted sabe dónde dan licencias para cabarets?”13.

Ramón (un miembro consagrado de la contracultura; es decir, la modernidad) y Tina (un personaje que se muestra como paleto) manifiestan una diferenciación evidente en imagen: Tina, de color azul oscuro (los colores oscuros nos remiten al Régimen, a Marina de Obregón y las viejitas con perlas ya descritas). Ramón viste con un abrigo de piel blanco y beis y gafas modernas. Al final, él se apiada de Tina y la lleva consigo, cargando con su maleta.

La secuencia en la que Tina sufre un punto de inflexión en el que se transforma en moderna, es una de las más psicodélicas de la película ${ }^{14}$. Tina, a la que de repente le ha crecido una mata de pelo negro, se sienta en una esquina, vestida 
de blanco en contraste con la pared negra, sentada con las piernas cruzadas, como si fuera a comenzar a meditar. Por ella, entonces, van pasando luces de color que se reflejan en su ropa, con forma de medusas. La música de fondo imita al reverb de los amplificadores. Tina cierra los ojos y por su rostro se arrastran las medusas rojas, sufriendo una catarsis de modernidad que el resto de protagonistas observa extasiado.

En la secuencia final de Tina ${ }^{15}$, en la que el personaje desaparece de la película, ella se encuentra ya plenamente introducida en la modernidad. Viste de una manera alegre y colorida y lleva atada una corbata en la frente. Junto al resto de personajes, ha ayudado a desbaratar varios de los conjuntos pendientes de actuar en el Festival de MundoCanal. En su hijo podemos ver representada la imagen de su pasado: vestido con una gorra y un abrigo azul marino. Tina se desmorona y empieza a llorar. "Nunca os volveré a dejar solos a ti y a tus hermanitos". El hijo hace un ademán de impaciencia. El resto de los personajes contempla la escena con incredulidad. La mujer vuelve al campo y la contracultura (la modernidad) vuelve a quedar en manos de los habitantes de la ciudad.

\section{Conclusiones}

Podríamos continuar rescatando diálogos jocosos a lo largo de todo el psicodélico filme de Zulueta. Sin embargo, aquí quedan expuestas las características contraculturales más generales que definen la cultura underground desarrollada durante la dictadura franquista en Madrid: el anonimato, la libertad, el esnobismo y la actitud, conducida a través de la música, como única protesta posible ante la autoridad hegemónica. Aunque la película termina con un happy end en el que la contracultura perdona al mainstream, siendo una de las protagonistas la ganadora del Festival de la Canción de MundoCanal, no podemos acertar a comprender este final como feliz: la contracultura abraza la fagocitación del Sistema a cambio de la paz con su casero, que acepta por fin no subirles el alquiler de la tienda, ¿no es esta, acaso, la definición de la Transición

\footnotetext{
${ }_{15}$ Minuto 62 del metraje.
} 
Democrática, representada musicalmente en La Movida? Seguramente sea algo que Zulueta no se llegó a plantear. Tampoco entra dentro de nuestro objeto de estudio. Nos quedamos con la imagen colorida de una España ficticia, y la palabra underground escondida entre las melenas de sus representantes.

De todas formas, es preciso recordar que el objetivo principal de esta investigación era rescatar los rasgos principales de la contracultura madrileña durante el Franquismo a través de los diálogos y las imágenes de 1,2,3, al escondite inglés. En respuesta a este objetivo, se puede establecer que estos diálogos e imágenes son definidos por términos como el anonimato que ofrece la ciudad frente a la vida en el pueblo, la libertad de consumo de productos culturales alternativos, así como la actitud de las bandas frente al antiguo régimen.

Respecto a los objetivos secundarios, se demuestra que la música ejercía de hilo conductor de la contracultura durante la dictadura a través de los videoclips y grupos musicales que representan a la modernidad del momento, así como por la significación que tiene "prestarse" a interpretar la canción en su círculo cultural. Sin embargo, no podemos afirmar que toda la música que encontramos en la película pertenezca a una esfera underground (Los Bravos o Fórmula V resultaban grupos de gran fama en el momento, y tampoco podemos olvidar que las bandas participantes fueron contactadas por José María Iñigo, de posición cómoda dentro del Régimen) o que sólo la música sea la que ejerce de hilo conductor de una propuesta, como veremos a continuación, a la hora de hablar sobre las conclusiones que extraemos de las palabras analizadas en el artículo.

En referencia a si existe una clara distinción entre la cultura juvenil y la cultura normativa de la dictadura, nos podemos remitir a las imágenes ( $\mathrm{F}_{1}$ a $\mathrm{F}_{5}$ ) del artículo para concluir que, efectivamente, a lo largo de la película la juventud se muestra con colores y tonos flúor, mientras que los personajes del viejo Régimen, siempre llevan tonos grises y blanco y negro, estableciendo así una diferenciación visual clara.

En cuanto a los planteamientos de partida, se puede afirmar que, a lo largo de la película encontramos patrones de conducta y actuación que se repiten durante todo el metraje. El más representativo respecto a imagen es el ya mencionado contraste del uso del color entre los personajes pertenecientes al viejo Régimen 
(paleta de blancos y negros), frente a la modernidad (paleta de colores flúor). El más significativo en relación a la actitud es la pose lánguida y pasota de las bandas frente a la afectación de Marina de Obregón a la hora de interpretar su tema.

En lo referente a las palabras, encontramos en ellas leves alusiones a la situación del momento, utilizando indirectas o chistes internos que sólo pueden ser comprendidos una vez se conoce el contexto contracultural de la época. Los patrones de conducta contraculturales que evidencian la actitud de la cultura underground madrileña durante el Franquismo, de los que hablábamos en el Epígrafe 2, donde están presentes a lo largo de los protovideoclip que la película incluye. Las bandas mantienen un mismo tipo de conducta, estética y actitud a la hora de interpretar sus temas. También se expone la representación, en palabra e imagen, del patrón contracultural, a la hora de observar el personaje de Tina, que es ajena a la contracultura, comienza a adoptar una actitud underground, que le lleva incluso a actuar contra las bandas elegidas para actuar en el Festival de MundoCanal. Este último "desbaratamiento" es sin duda otro rasgo que permite ver el enfrentamiento entre el antiguo Régimen y la joven modernidad.

También descubrimos, a través de estas palabras, que la música no es el único hilo conductor, como ya adelantábamos al comienzo de las conclusiones. Encontramos en el uso jocoso y cómico del guion un tipo de protesta primitiva e implícita a la hora de lanzar mensajes subversivos: el humor. Se trata de una conclusión natural, dado que las señales de vida de una contracultura madrileña durante el franquismo que encontramos en la cinta de Zulueta van siempre acompañadas de un tono de comicidad. Son rasgos tratados a modo de chiste o de chascarrillo. El humor permite que este mensaje de protesta cale en el espectador de una manera sencilla e inocua a ojos de la autoridad.

\section{Referencias bibliográficas}

Carmona, P. C. (2012). Libertarias y contraculturales: el asalto a la sociedad disciplinaria: entre Barcelona y Madrid 1965-1979 (Doctoral dissertation, Universidad Complutense de Madrid).

Neira, F. Canciones que cambian la vida. 9 de octubre 2018. El País.

Oblitas, J. R. V., \& Parra, V. F. G. (2011). 1, 2, 3, al escondite inglés: la locura pop de Ivan Zulueta. In Cine español: arte, industria y patrimonio cultural (pp. 287-300). Instituto de la Cinematografía y de las Artes Audiovisuales. 
Otaola González, P. (2015). Canción española e identidad nacional en la España franquista: Manolo Escobar.

Ramis Plomer, A. (2014). We're not gonna take it: La censura franquista en la música pop-rock anglosajona. Testimonios, censura y medios de comunicación (1939-1975).

Rodríguez, V. S. (2014). La Banda Sonora Musical en el cine español y su empleo en la configuración de tipologías de mujer (1960-1969) (Vol. 335). Ediciones Universidad de Salamanca. Rodríguez, V.S.

Toro, C. Los Beatles en España, iqué concierto el de aquella noche! 29 junio 2015. El Mundo. 